\title{
StressChip as a High-Throughput Tool for Assessing Microbial Community Responses to Environmental Stresses
}

\author{
Aifen Zhou, ${ }^{\dagger}$ Zhili He, $^{\dagger}$ Yujia Qin, ${ }^{\dagger}$ Zhenmei Lu, ${ }^{\dagger}{ }^{\dagger}$ Ye Deng, ${ }^{\dagger}$ Qichao Tu, ${ }^{\dagger}$ Christopher L. Hemme, ${ }^{\dagger}$ \\ Joy D. Van Nostrand, ${ }^{\dagger}$ Liyou Wu, ${ }^{\dagger}$ Terry C. Hazen,,$^{\S, \|}$ Adam P. Arkin, ${ }^{\perp}$ and Jizhong Zhou*, ${ }^{\dagger}, \#, \Delta$ \\ ${ }^{\dagger}$ Institute for Environmental Genomics, Department of Microbiology and Plant Biology, University of Oklahoma, Norman, \\ Oklahoma 73019, United States \\ ¥College of Life Sciences, Zhejiang University, Hangzhou 310058, China \\ ${ }^{\S}$ Department of Civil and Environmental Engineering, The University of Tennessee, Knoxville, Tennessee 37996, United States \\ "Biosciences Division, Oak Ridge National Laboratory, Oak Ridge, Tennessee 37831-6342, United States \\ ${ }^{\perp}$ Physical Biosciences Division and ${ }^{\#}$ Earth Sciences Division, Lawrence Berkeley National Laboratory, Berkeley, California 94720 , \\ United States \\ ${ }^{\Delta}$ State Key Joint Laboratory of Environment Simulation and Pollution Control, School of Environment, Tsinghua University, \\ Beijing 100084, China
}

\section{Supporting Information}

\begin{abstract}
Microbial community responses to environmental stresses are critical for microbial growth, survival, and adaptation. To fill major gaps in our ability to discern the influence of environmental changes on microbial communities from engineered and natural environments, a functional genebased microarray, termed StressChip, has been developed. First, 46 functional genes involved in microbial responses to environmental stresses such as changes to temperature, osmolarity, oxidative status, nutrient limitation, or general stress response were selected and curated. A total of 22,855 probes were designed, covering 79,628 coding sequences from 985 bacterial, 76 archaeal, and 59 eukaryotic species/strains. Probe specificity was computationally verified. Second, the

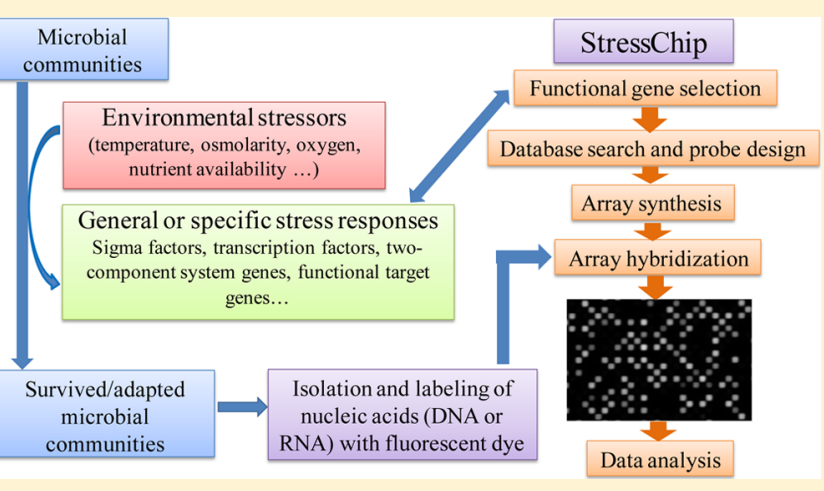
usefulness of functional genes as indicators of stress response was examined by surveying their distribution in metagenome data sets. The abundance of individual stress response genes is consistent with expected distributions based on respective habitats. Third, the StressChip was used to analyze marine microbial communities from the Deepwater Horizon oil spill. That functional stress response genes were detected in higher abundance $(p<0.05)$ in oil plume compared to nonplume samples indicated shifts in community composition and structure, consistent with previous results. In summary, StressChip provides a new tool for accessing microbial community functional structure and responses to environmental changes.
\end{abstract}

\section{INTRODUCTION}

Microorganisms are the most diverse group of life presently known, inhabiting almost every imaginable environment on Earth. They play important roles in ecosystem functioning, such as biogeochemical cycling of carbon $(\mathrm{C})$, nitrogen $(\mathrm{N})$, sulfur $(\mathrm{S})$, phosphorus $(\mathrm{P})$, and various metals. The composition, structure, and functions of microbial communities are dynamic and sensitive to environmental changes. Given the complexity of microbial communities and divergent molecular mechanisms of microbial responses to environmental stress, it remains a great challenge to monitor stress responses of microbial communities to environmental changes. Therefore, development of rapid, specific, sensitive, and high-throughput quantitative tools for detecting the responses of microbial communities to environmental stresses is greatly needed.
The adaptation of microbial communities to environmental changes involves the regulation of microbial populations, gene expression and activity, and/or genetic/evolutionary changes. Extensive studies in model microorganisms such as Escherichia coli and Bacillus subtilis have demonstrated that a complex global regulatory network including regulation at the transcriptional or post-transcriptional levels are important aspects of stress responses. ${ }^{1-3}$ For example, two-component systems, such as desK-desR, control the cold induction of a desaturase gene, des, which is important for keeping proper membrane fluidity at low temperature; ${ }^{4}$ regulatory gene $h r c A$ and chaperon machinery

Received: August 27, 2012

Revised: July 22, 2013

Accepted: July 26, 2013 
genes dnaK, grpE, groES, and groEL are involved in heat shock responses. ${ }^{5}$ The ProU system genes proX, proV, and proW play important roles in osmotic stress response. ${ }^{6,7}$ Due to the difficulty of monitoring post-transcriptional changes, regulatory and/or functional genes that have been demonstrated to be involved in stress response in pure cultures are targets for analyzing microbial communities in response to environmental changes.

Key functional genes involved in microbial functional processes have been shown to be very useful markers for examining functional diversity, composition, structure, and metabolic potential/activity of microbial communities with microarray platforms, namely, functional gene arrays (FGAs)..$^{8-10}$ Comprehensive FGAs, such as GeoChip, have been developed and applied to analyze microbial communities from different habitats, ${ }^{11-16}$ and experimental results demonstrate GeoChips are specific, sensitive, and quantitative tools to rapidly profile microbial communities and link these communities to ecosystem functioning. ${ }^{8}$ Great effort has been undertaken to optimize the probe design and improve the hybridization specificity and sensitivity of GeoChip. ${ }^{11,13,14,17-23}$ Whole-genome amplification protocols for microbial community DNA/RNA samples were established to overcome limitations due to low biomass or low DNA/RNA yield from community samples. ${ }^{22,24}$ However, highthroughput cultivation-independent tools for monitoring microbial community responses to environmental stresses are still lacking.

In this study, we have developed a stress genes-based microarray, termed StressChip, for the assessment of microbial responses to environmental stresses. Functional genes involved in general and specific stress responses to changes of temperature, osmolarity, oxygen level, and nutrient limitation were included. We primarily focus on the selection of the stress response genes, computational evaluation of the probes, analysis of the distribution of the functional genes in metagenomes from various environmental microbial communities, and application of the StressChip to analyze seawater microbial communities. To our knowledge, this is the first metagenomic tool developed for comprehensive examination of microbial community responses to environmental stresses.

\section{MATERIALS AND METHODS}

2.1. Selection of Key Functional Genes. A total of 46 functional genes have been selected to target general and specific stress responses (Table 1).

(i). Sigma Factor, General Stress Response, and Stringent Response. We selected four sigma factors, ${ }^{25}$ including $\sigma^{70}$ (RpoD, the "housekeeping" sigma factor or primary sigma factor), $\sigma^{38}$ (RpoS, induced during entry into stationary phase and controls the general stress response in Gram-negative bacteria), ${ }^{26} \sigma^{32}$ (RpoH, the heat shock sigma factor), and $\sigma^{24}$ (RpoE, the extracytoplasmic/extreme heat stress sigma factor), katE (haem-catalase) ${ }^{27}$ for general stress response, and $o b g E$ (encoding a GTPase involved in keeping low intracellular concentrations of ppGpp) for stringent response. ${ }^{28-31}$

(ii). Temperature Stresses. Fluctuations in temperature are often encountered by environmental microorganisms. Most of the heat shock proteins are molecular chaperones or ATPdependent proteases which promote renaturation or degradation of partially unfolded proteins. ${ }^{32}$ The microbial cold shock response involves an increase in the proportion of unsaturated fatty acids (UFAs) in membrane lipids and the induction of cold shock proteins (Csp) as chaperones to eliminate secondary
Table 1. Summary of the StressChip probes

\begin{tabular}{|c|c|c|c|c|c|}
\hline stress response & $\begin{array}{l}\text { gene } \\
\text { name }\end{array}$ & $\begin{array}{l}\text { no. of } \\
\text { probes }\end{array}$ & $\begin{array}{l}\text { sequence- } \\
\text { specific } \\
\text { probes }\end{array}$ & $\begin{array}{l}\text { group- } \\
\text { specific } \\
\text { probes }\end{array}$ & $\begin{array}{l}\text { covered } \\
\text { CDS }\end{array}$ \\
\hline \multirow[t]{4}{*}{ sigma factor } & $\sigma^{24}$ & 475 & 57 & 418 & 1008 \\
\hline & $\sigma^{32}$ & 1990 & 225 & 1765 & 4284 \\
\hline & $\sigma^{38}$ & 371 & 26 & 345 & 1026 \\
\hline & $\sigma^{70}$ & 1881 & 106 & 1775 & 5249 \\
\hline $\begin{array}{l}\text { general stress } \\
\text { response }\end{array}$ & katE & 961 & 172 & 789 & 2326 \\
\hline $\begin{array}{l}\text { stringent } \\
\text { response }\end{array}$ & $o b g E$ & 1264 & 54 & 1210 & 3990 \\
\hline \multirow[t]{5}{*}{ heat shock } & $h r c A$ & 644 & 130 & 514 & 1467 \\
\hline & $d n a K$ & 262 & 0 & 262 & 715 \\
\hline & GroES & 33 & 10 & 23 & 69 \\
\hline & groEL & 153 & 51 & 102 & 302 \\
\hline & $\operatorname{grp} E$ & 563 & 24 & 539 & 1295 \\
\hline \multirow[t]{4}{*}{ cold shock } & $\operatorname{des} R$ & 9 & 0 & 9 & 18 \\
\hline & $\operatorname{des} K$ & 7 & 0 & 7 & 14 \\
\hline & $\operatorname{csp} A$ & 36 & 0 & 36 & 88 \\
\hline & $\operatorname{csp} B$ & 18 & 0 & 18 & 50 \\
\hline \multirow[t]{4}{*}{ osmotic stress } & opuE & 25 & 1 & 24 & 65 \\
\hline & proX & 50 & 23 & 27 & 80 \\
\hline & proV & 364 & 14 & 350 & 1106 \\
\hline & prow & 18 & 3 & 15 & 35 \\
\hline \multirow[t]{5}{*}{ oxidative stress } & perR & 32 & 3 & 29 & 69 \\
\hline & oxyR & 522 & 15 & 507 & 1454 \\
\hline & $a h p C$ & 903 & 42 & 861 & 2437 \\
\hline & $a h p F$ & 369 & 31 & 338 & 1182 \\
\hline & katA & 90 & 13 & 77 & 204 \\
\hline \multirow[t]{9}{*}{ oxygen limitation } & $f n r$ & 1925 & 2 & 1923 & 10160 \\
\hline & narG & 1278 & 502 & 776 & 3501 \\
\hline & narH & 157 & 22 & 135 & 410 \\
\hline & narJ & 99 & 20 & 79 & 198 \\
\hline & narl & 323 & 36 & 287 & 1004 \\
\hline & $c y d A$ & 131 & 3 & 128 & 333 \\
\hline & $c y d B$ & 159 & 5 & 154 & 430 \\
\hline & $\operatorname{arcA}$ & 67 & 5 & 62 & 207 \\
\hline & $\operatorname{arcB}$ & 58 & 30 & 28 & 86 \\
\hline \multirow[t]{2}{*}{ glucose limitation } & $b g l P$ & 44 & 2 & 42 & 88 \\
\hline & $b g l H$ & 42 & 1 & 41 & 93 \\
\hline \multirow{6}{*}{$\begin{array}{l}\text { phosphate } \\
\text { limitation }\end{array}$} & phoA & 239 & 40 & 199 & 623 \\
\hline & phoB & 597 & 27 & 570 & 1455 \\
\hline & pstS & 322 & 38 & 284 & 698 \\
\hline & pstA & 803 & 80 & 723 & 1915 \\
\hline & $p s t B$ & 723 & 0 & 723 & 3522 \\
\hline & pstC & 2800 & 0 & 2800 & 16660 \\
\hline \multirow{3}{*}{$\begin{array}{l}\text { nitrogen } \\
\text { limitation }\end{array}$} & $g \ln A$ & 1296 & 7 & 1289 & 7079 \\
\hline & $g \ln R$ & 158 & 4 & 154 & 894 \\
\hline & $\operatorname{tnr} A$ & 7 & 0 & 7 & 21 \\
\hline \multirow[t]{2}{*}{ protein stress } & $c t s R$ & 159 & 2 & 157 & 647 \\
\hline & $c l p C$ & 428 & 12 & 416 & 1071 \\
\hline total & 46 & 22855 & 1838 & 21017 & 79628 \\
\hline
\end{tabular}

structures and restore RNA functionality. ${ }^{33}$ Functional genes targeting heat shock such as chaperon machinery genes $d n a K$, grpE, groES, and groEL and the regulatory gene $h r c A^{5}$ or cold shock such as cold shock protein genes $\operatorname{csp} A$ and $\operatorname{csp} B^{34,35}$ and two-component system genes desK-des $R^{4}$ exclusively controlling the cold-induction of a desaturase gene des were included in the StressChip. 
(iii). Osmolarity. Cells respond to osmotic shock by adjusting the cellular concentration of osmolytes or compatible solutes. ${ }^{36}$ We selected $o p u E$ (osmoprotectantuptake, single component sodium/solute symporter with high affinity for proline ${ }^{37,38}$ ) and the ProU system genes proX, proV, and proW (with a broad substrate specificity for osmoprotectants but a clear preference for glycine betaine and proline betaine ${ }^{6,7}$ ) for monitoring microbial responses to osmotic stress.

(iv). Oxidative Stress and Oxygen Limitation. Oxidative stress represents an imbalance between the production and scavenging of reactive oxygen species (ROS). We selected the functional genes $a h p C F$ (alkyl hydroperoxide reductase) and katA (catalase) involved in detoxification of ROS and regulatory genes perR and $o x y R$ for oxidative stress response. ${ }^{39-41}$ When the oxygen level decreases, microorganisms adjust their energy metabolism for survival. Cytochrome genes ( $c y d A$ and $c y d B$ ), activated when oxygen becomes limiting, regulatory genes for cyd $A B$ expression such as $f n r$ and two-component system genes $(\operatorname{arc} A$ and $\operatorname{arcB}),{ }^{42,43}$ and nitrate reductase genes (narG, narH, narJ, and narI) allowing nitrate as an electron acceptor grown anaerobically ${ }^{44}$ were chosen to target oxygen limitation.

(v). Nutrition Limitation. Limited nutrition such as glucose, phosphate, and nitrogen is a common stressor faced by microbes in the natural environment. We selected $b g l P$ (aryl-beta-glucosidespecific enzyme II) and $b g l H$ (phospho-beta-glucosidase) for utilization of aryl- $\beta$-glucosides as alternative carbon sources ${ }^{45}$ to target glucose limitation. Phosphate is an essential nutrient for microbial metabolism because the majority of the building blocks of cellular functional structures are phosphorylated. Phosphatespecific transport system (Pst, the main inorganic phosphate $(\mathrm{Pi})$ uptake system under phosphate limiting conditions) genes pstS, pst $A, p s t B$, and $p s t C$, alkaline phosphatase gene phoA liberating free $\mathrm{Pi}$ from external sources, and their regulator gene $p h o B$ (response regulator) were selected for phosphate limitation. $^{46-52}$ The regulation of nitrogen $(\mathrm{N})$ metabolism upon $\mathrm{N}$ limitation is quite diverse among different microbial organisms. Glutamine serves as a sensor of external nitrogen availability in enteric bacteria. ${ }^{53}$ Glutamine synthase gene $g \ln A$ and regulatory genes $t n r A$ and $g \ln R$ were selected for nitrogen limitation. ${ }^{54}$

(vi). Protein Stress. Overproduction of recombinant proteins in microbial cells stimulates protein stress. ${ }^{55,56}$ Accumulation of recombinant protein induces the activation of heat shock sigma factor $\sigma^{32}$ and $\sigma^{32}$-dependent genes. ${ }^{57}$ We selected $c l p C$ (ATPase subunit in the $\mathrm{Clp}$ machinery) and regulator gene $c t s R$ to target protein stress. ${ }^{58-60}$

2.2. Retrieval and Verification of Functional Gene Sequences. Sequence retrieval was performed using the GeoChip design pipeline. ${ }^{14}$ Briefly, for each functional gene, keywords such as the name of the target gene or protein, its abbreviation or enzyme commission number (EC), and affiliated domains (bacteria, archaea, and fungi) were listed as a query and submitted to the GenBank Protein Database to fetch amino acid sequences. Then, the sequences were downloaded and verified by HMMER 2.3.2 (Ashburn, VA, USA) with seed sequences, whose functions have been experimentally characterized in certain microorganisms. Finally, the nucleic acid sequences for the confirmed protein sequences were obtained from GenBank and used for probe design. All sequences were downloaded from the GenBank database before Feb. 52010.

2.3. Oligonucleotide Probe Design, Computational Evaluation of Probes, and Construction of The StressChip. Oligonucleotide probes were designed with an improved version of CommOligo, ${ }^{20}$ which has group-specific probe design
Table 2. Microbial Domain and Phylum Covered by StressChip

\begin{tabular}{|c|c|c|c|c|}
\hline domain & phylum & $\begin{array}{l}\text { no. of } \\
\text { species }\end{array}$ & $\begin{array}{l}\text { no. of } \\
\text { probes }\end{array}$ & $\begin{array}{c}\text { no. of } \\
\text { covered CDS }\end{array}$ \\
\hline \multirow[t]{7}{*}{ archaea } & & 76 & 709 & 2417 \\
\hline & Crenarchaeota & 19 & 99 & 411 \\
\hline & Euryarchaeota & 52 & 573 & 1904 \\
\hline & Korarchaeota & 1 & 7 & 24 \\
\hline & Nanoarchaeota & 1 & 1 & 2 \\
\hline & Thaumarchaeota & 2 & 8 & 28 \\
\hline & unclassified & 1 & 21 & 48 \\
\hline \multirow[t]{28}{*}{ bacteria } & & 985 & 21689 & 76324 \\
\hline & Acidobacteria & 4 & 145 & 340 \\
\hline & Actinobacteria & 124 & 1931 & 6381 \\
\hline & Aquificae & 5 & 102 & 302 \\
\hline & Bacteroidetes & 62 & 1069 & 2957 \\
\hline & CandidatusPoribacteria & 1 & 4 & 4 \\
\hline & Chlamydiae & 9 & 66 & 331 \\
\hline & Chlorobi & 11 & 265 & 658 \\
\hline & Chloroflexi & 8 & 297 & 888 \\
\hline & Cyanobacteria & 23 & 1215 & 3618 \\
\hline & Deferribacteres & 1 & 24 & 56 \\
\hline & Deinococcus-Thermus & 9 & 145 & 417 \\
\hline & Dictyoglomi & 2 & 21 & 62 \\
\hline & Elusimicrobia & 2 & 18 & 45 \\
\hline & Fibrobacteres & 1 & 22 & 54 \\
\hline & Firmicutes & 221 & 4063 & 18397 \\
\hline & Fusobacteria & 12 & 78 & 188 \\
\hline & Gemmatimonadete s & 1 & 37 & 94 \\
\hline & Lentisphaerae & 2 & 31 & 72 \\
\hline & Nitrospirae & 2 & 35 & 85 \\
\hline & Planctomycetes & 8 & 276 & 531 \\
\hline & Proteobacteria & 415 & 9931 & 35403 \\
\hline & Spirochaetes & 17 & 122 & 472 \\
\hline & Synergistetes & 4 & 65 & 153 \\
\hline & Tenericutes & 19 & 98 & 378 \\
\hline & Thermotogae & 12 & 101 & 440 \\
\hline & Verrucomicrobia & 7 & 256 & 577 \\
\hline & unclassified bacterium & 3 & 1272 & 3421 \\
\hline \multirow[t]{6}{*}{ eukaryota } & & 59 & 457 & 887 \\
\hline & Ascomycota & 46 & 386 & 753 \\
\hline & Basidiomycota & 9 & 64 & 123 \\
\hline & Glomeromycota & 1 & 2 & 3 \\
\hline & Microsporidia & 2 & 3 & 6 \\
\hline & Neocallimastigomycota & 1 & 2 & 2 \\
\hline total & & 1120 & 22855 & 79628 \\
\hline
\end{tabular}

features. Oligonucleotide probes were chosen on the basis of the following criteria: (i) gene-specific probes: targeting a single sequence and having $\leq 90 \%$ sequence identity, $\leq 20$-base continuous stretch, and $\geq-35 \mathrm{kcal} / \mathrm{mol}$ free energy with their nontarget sequences; ${ }^{21}$ (ii) group-specific probes: targeting a group of highly homologous sequences exclusively and having $\geq 96 \%$ of sequence identity, $\geq 35$-base continuous stretch, and $\leq-60 \mathrm{kcal} / \mathrm{mol}$ of free energy within the group. ${ }^{19}$ All designed probes (50-mer) were verified by the in-house software ProbeChecker. GenBank (NR) nucleic acid database was used for computational specificity evaluation of the probes. The StressChip was manufactured by NimbleGen (Madison, WI, USA). The StressChip design has been integrated into the more comprehensive GeoChip 4.0, ${ }^{61,62}$ the latter being used to analyze the samples presented in this study. 




Figure 1. Distribution of probes and targets for different stress responses in the StressChip.

2.4. Analysis of the Distribution of Stress Functional Genes in Metagenomes from Different Environments. Seven metagenomes from different environments were downloaded from the Joint Genome Institute Integrated Microbial Genomes (IMG) database (http://img.jgi.doe.gov/cgi-bin/m/ main.cgi). These samples represent four ecosystem types including marine, freshwater, nonmarine saline and alkaline, and desert soil. Detailed information of the metadata is listed in Table S1, Supporting Information. Distribution of 46 stress functional genes in these metagenomes was selected from the abundance profiles of COG function in these metagenomes. The hierarchical linkages of the metagenomes were generated with Gene Cluster 3.0.

2.5. Target DNA Preparation, Hybridization, and StressChip Data Analysis. Seawater samples were collected from the Gulf of Mexico between May 27 and June 2, 2010 after the Deepwater Horizon oil spill occurred. ${ }^{61}$ Eight samples (BM053, BM054, BM057, BM058, BM064, OV201, OV401, and OV501) from the MC252 dispersed oil plume and five samples (OV003, OV004, OV009, OV013, OV014) from a nonplume area at a depth of $1099-1219 \mathrm{~m}^{62}$ were analyzed in this study.

Approximately $100 \mathrm{ng}$ of DNA isolated from $0.22 \mu \mathrm{m}$ polyethylsulfone membranes filters (MO BIO Laboratories, Inc., Carlsbad, CA $)^{61}$ was amplified with the Templiphi kit (GE Healthcare; Piscataway, NJ). ${ }^{22}$ Cy3 labeling of the amplified DNA $(2 \mu \mathrm{g})$ and hybridization were performed as described previously. ${ }^{62}$ After a $16 \mathrm{~h}$ hybridization at $42{ }^{\circ} \mathrm{C}$ with $40 \%$ formamide on a MAUI hybridization station (BioMicro Systems, Salt Lake City, UT, USA), the arrays were scanned with a NimbleGen MS200 microarray scanner (RocheNimbleGen, Madison, WI, USA) at a laser power of $100 \%$ and $100 \%$ PMT (photomultiplier tube).

The raw data from hybridization was preprocessed by removing spots with signal-to-noise ratio (SNR) less than 2.0. SNR was calculated as (average of signal pixels in the probe space - average of background pixels in four void spots)/ standard deviation of background pixels. Genes detected in only one sample were removed. Processed StressChip data (Table S2) is available in the Supporting Information. Canonical correspondence analysis (CCA) was used to link the stress responses of the microbial communities to environmental variables.

\section{RESULTS AND DISCUSSION}

3.1. Features of the StressChip. A total of 46 functional gene families with 40 targeting specific stress response pathways including nine for temperature shift, four for osmotic stress, 14 for oxidative stress/oxygen limitation, 11 for nutrient limitation, and two for protein stress were covered by the StressChip (Table 1). Also, four sigma factors, one general stress response gene, and one stringent response gene were included in the StressChip (Table 1). A total of 22,855 probes covering 79,628 gene sequences with about $8.0 \%$ (1838 probes) as sequencespecific probes and about $92.0 \%(21,017$ probes $)$ as groupspecific probes (Table 1) were designed. Of these, 21,689 probes (94.9\%) target 985 bacterial, 709 probes (3.1\%) target 76 archaeal, and 457 probes (2.0\%) target 59 eukaryotic species/ strains (Table 2). Percentages of probes and covered CDS sequences in the StressChip are $27.8 \%$ and $19.0 \%$ for nitrogen limitation, $23.4 \%$ and $22.5 \%$ for oxygen limitation, $13.6 \%$ and $11.5 \%$ for phosphate limitation, $14.6 \%$ and $20.7 \%$ for sigma factors (Figure 1). In addition, internal controls, including degenerate probes for $16 \mathrm{~S}$ rRNA gene as positive controls and probes for hypothetical genes of hyperthermophiles as negative controls, ${ }^{14}$ and 50-mer common oligonucleotide reference standard (CORS) ${ }^{23}$ were randomly localized in each array for quality control and data normalization, respectively.

3.2. Computational Evaluation of the StressChip. A computational analysis of the specificity of all probes in terms of sequence identity, stretch length, and free energy of a probe to its nontargets was performed. All probes fell in the desired ranges of sequence identity, stretch length, or free energy with only a small portion of the designed probes close to the thresholds. For genespecific probes, $6.2 \%$ of the probes had $88 \%$ identities with their closest nontargets (Figure $2 \mathrm{a}$ ), $4.8 \%$ of the probes with 20 bases of continuous match with nontargets (Figure $2 \mathrm{~b}$ ), and $12.7 \%$ of the probes with free energy of -35 to $-30 \mathrm{kcal} / \mathrm{mol}$ with nontargets (Figure 2c). For group-specific probes, about $99 \%$ of the probes had more than $98 \%$ sequence identities with group targets including about $95.2 \%$ of the probes with $100 \%$ sequence identities to group targets (Figure 2d), about $96.9 \%$ of the probes had 50-base stretches with the group targets and only $1.4 \%$ of the probes had 35-39 continuous match with group targets (Figure $2 \mathrm{e}$ ), and $98.3 \%$ of the probes had free energy less than $-65 \mathrm{kcal} / \mathrm{mol}$ with group targets and only $1.7 \%$ of the probes had 




Maximal sequence identity of a probe to its non-targets (\%)

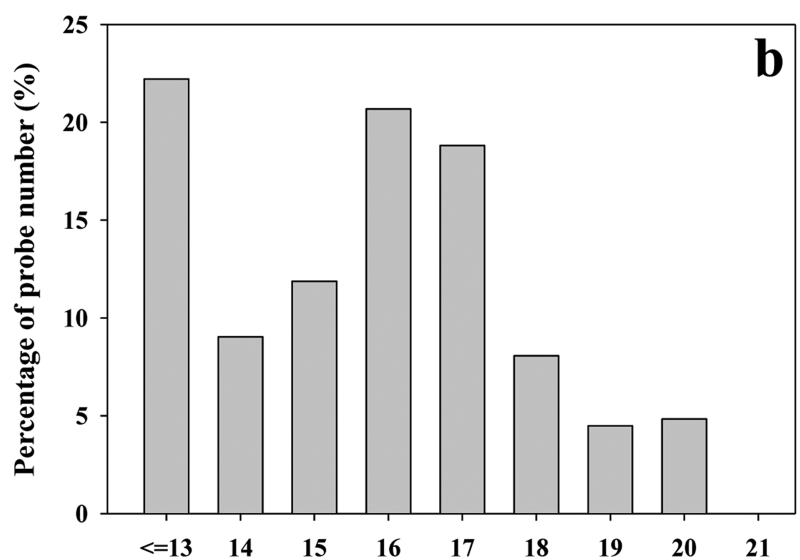

Maximal stretch length of a probe to its non-targets (base)



Minimal free energy of a probe to its non-targets $(\mathrm{kcal} / \mathrm{mol})$

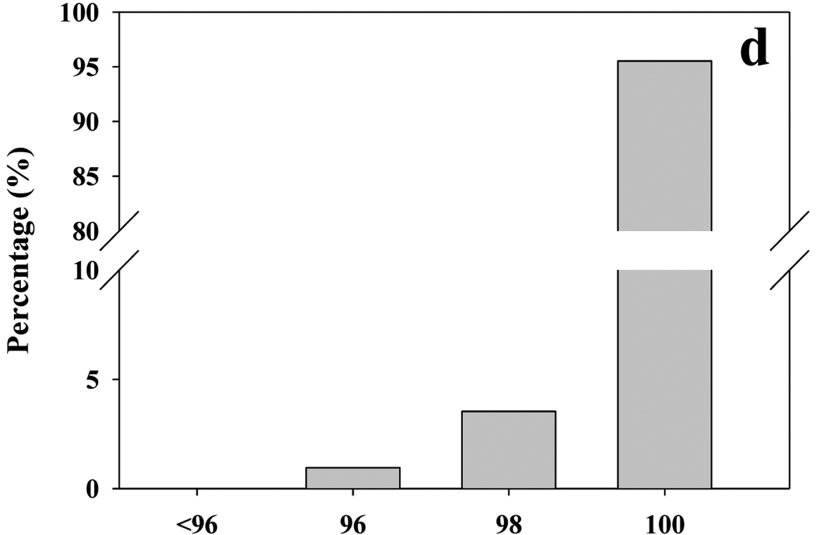

Minimal sequence identity of a probe to its group targets (\%)

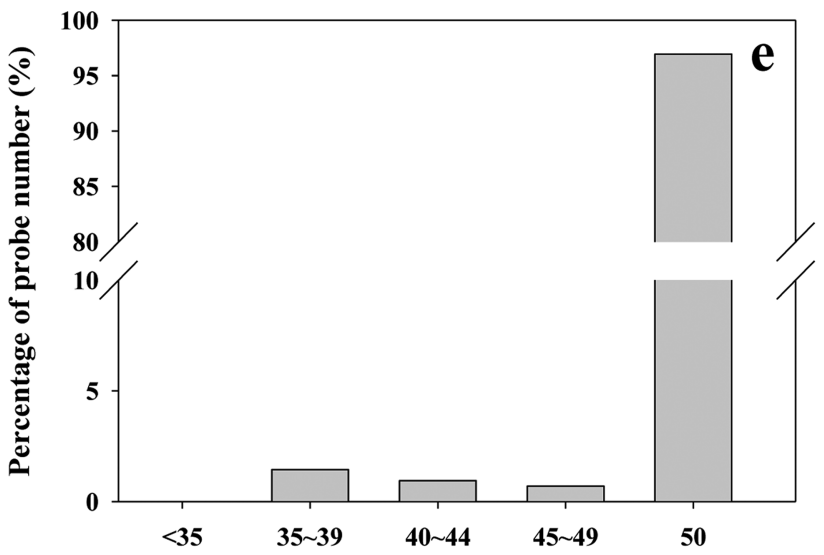

Minimal stretch length of a probe to its group targets (base)

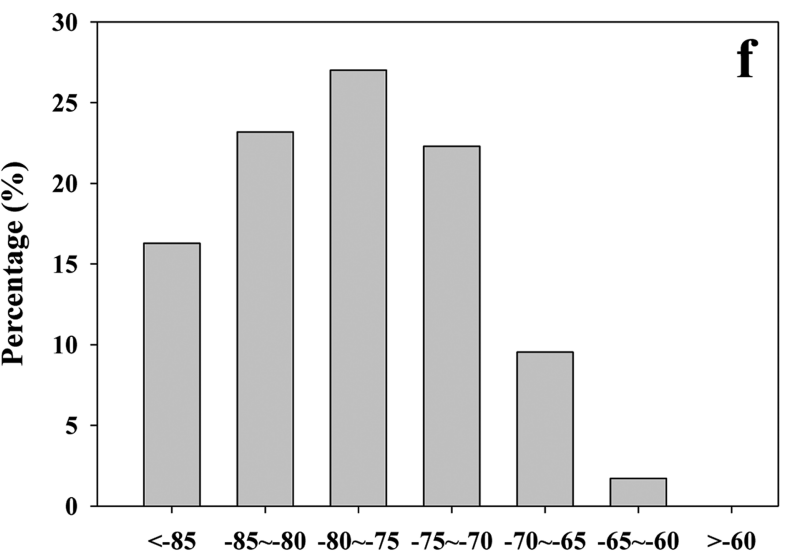

Maximal free energy of a probe to its group targets ( $\mathrm{kcal} / \mathrm{mol})$

Figure 2. Computational evaluation of all probes on the StressChip. Distribution of maximal sequence identity (a), maximal stretch length (b), and minimal free energy (c) of gene-specific probes to their nontargets; minimal sequence identity (d), minimal stretch length (e), and maximal free energy (f) of group-specific probes to their group targets are demonstrated.

free energy of -65 to $-60 \mathrm{kcal} / \mathrm{mol}$ with group targets (Figure $2 \mathrm{f}$ ). The results indicate all designed probes are specific to their corresponding targets. Previous experiments demonstrated that all designed probes were highly specific as evaluated with synthesized oligonucleotides and genomic DNA samples. ${ }^{13,14,17-19,21}$

3.3. Distribution of the Functional Genes in Different Environment Microbial Communities. Comprehensive analysis of prokaryotic genome sequences has demonstrated that gene expression regulation and signal integration have been strongly selected to enable rapid adaptation to environmental conditions, and larger genomes harbor more regulation genes. ${ }^{63,64}$ To examine whether the stress related functional genes in StressChip are good indicators of stress, the distribution of these genes in microbial communities from different environments was analyzed with seven online available metagenome data sets. Among these samples, marine samples 


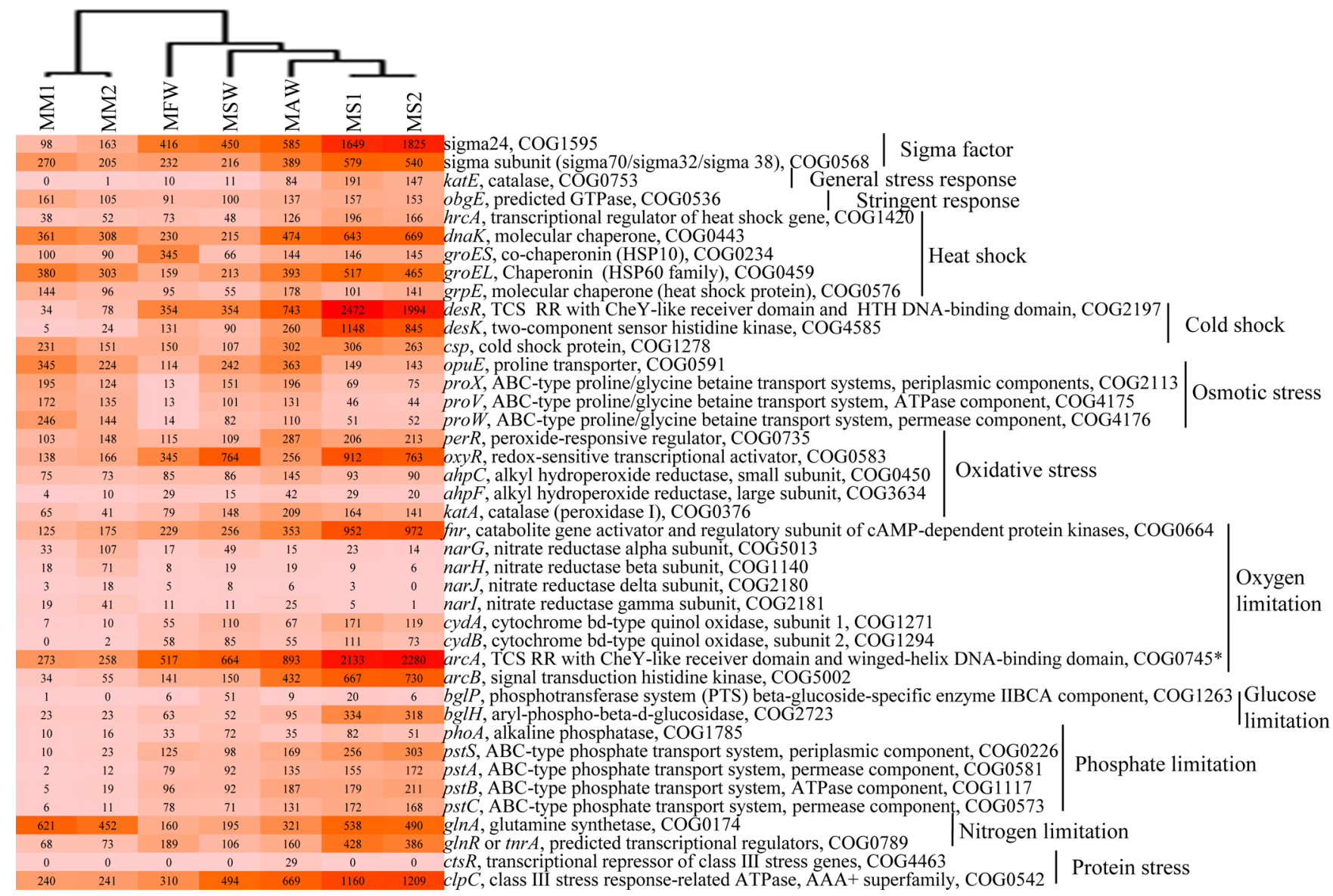

Figure 3. Distribution of stress functional genes in metagenome data sets from seven different environmental microbial communities. Numbers of gene counts for each functional gene are shown. Color scale: maximum: red; minimum: pink. Hierarchical cluster of seven microbial communities is generated with Gene Cluster 3.0. MM1, marine community sample line P from station P12 (Pacific Ocean) at a depth of $500 \mathrm{~m}$ sampled in June 2009; MM2, marine community sample F 10 from line P, station SI03 (Pacific Ocean) at a depth of $100 \mathrm{~m}$ sampled in February 2010; MFW, freshwater community from lentic Trout Bog Lake (Epilimnion) sampled on June 7, 2007, Wisconsin; MSW, saline water community from Great Salt Lake South Arm Stromatolite, Utah; MAW, saline and alkaline water sediment community from lentic Soda Lake (CA); MS1, desert soil community from FACE test site NTS_067, Nevada; and MS2, desert soil community from Dark Crust, Green Butte site, Colorado Plateau.

(MM1 and MM2) represent a relatively stable (not stressful) environment, and nonmarine saline and alkaline water samples (MSW and MAW) and desert soil samples (MS1 and MS2) represent relatively unstable (stressful) environments; a freshwater sample (MFW) may represent a less stressful environment than desert and nonmarine saline and alkaline water samples. As shown in Figure 3, the two marine samples cluster together in one clade; all other samples are in one clade, and two desert samples cluster together, suggesting the distribution of stress functional genes well represents the stressfulness of the environmental communities. Regulatory genes are enriched in communities in more stressful environments. Osmotic stress functional genes are enriched in saline water communities and marine microbial communities, which is consistent with the potential osmotic stress from the high salinity. Nutrient limitation genes are enriched in microbial communities from the barren desert. The abundances of stress functional genes are less in marine microbial communities (MM1, 1.08\%; MM2, $0.82 \%$ ) than others (MFW, $1.50 \%$; MSW, 1.54\%; MAW, $1.35 \%$; MS1, $1.66 \%$; MS2, 1.55\%). Stress responses have great potential as a controlling factor in shaping microbial communities. We might expect a highly stochastic environment to favor conservation of stress response genes whereas in a stable environment stress response genes tend to be lost. Therefore, the StressChip has the potential to assess the stress responses of microbial communities from different environments and/or their stability.

3.4. Application of StressChip on Microbial Community Samples Affected by Oil Contamination. The Deepwater Horizon oil leak, starting on April 20, 2010 at a depth of $1544 \mathrm{~m}$, released large amounts of oil and methane to the ocean. ${ }^{65}$ Previous studies on seawater samples taken from the vicinity of the wellhead after the oil spill demonstrated significant temporal community composition changes. ${ }^{61,65-67}$ With StressChip, a total of 1744 probes were detected. More genes $(1117 \pm 83)$ were detected in oil plume samples than nonplume samples $(852 \pm 30)$. The overall similarities of the stress response functional genes in plume and nonplume samples were low with two clearly separated clusters in the canonical correspondence analysis (CCA) plot (Figure 4, $p=0.05$ ). Result of the CCA also indicated that the functional structure of seawater microbial communities was shaped by environmental variables, such as total volatile hydrocarbon (HC), dissolved oxygen (DO), fluorometer detection of oil, 1,3,5-trimethylbenzene, small particle concentrations, and nitrate, which were closely correlated with the plume samples (Figure 4). A similar CCA plot was obtained in a previous GeoChip study of these microbial communities; $^{62}$ however, significantly correlated environmental variables were different. For example, several variables such as 


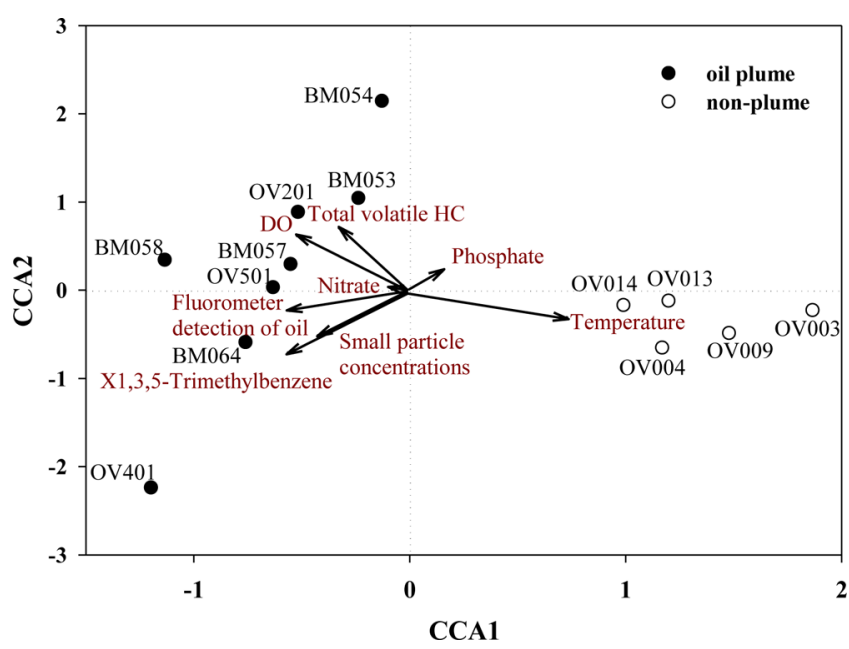

Figure 4. Canonical correspondence analysis of the relationship between the stress response genes of seawater microbial communities (symbols) and environmental factors (arrows).

1,3,5-trimethylbenzene, small particle concentrations, and nitrate did not appear in the CCA plot of GeoChip data; correlation of total extractable petroleum $\mathrm{HC}$ and GeoChip functional genes was not observed here. Significantly more probes for sigma factors, the stringent response gene $o b g E$, general stress response $k a t E$ and functional genes involved in heat shock, oxidative stress, oxygen limitation, phosphate limitation, or nitrogen limitation were detected in plume than in nonplume samples (Table S2 and Figure S1, Supporting Information). Such increases may be largely due to a sudden carbon input into the aquatic system, which could stimulate a microbial community shift toward copiotrophs and rapid response to changing environmental conditions by utilizing a range of carbon sources. ${ }^{68}$

A metagenomics study of plume (BM058 and OV201) and nonplume (OV003) communities ${ }^{66}$ demonstrated obvious community composition changes within $6 \mathrm{~h}$ (OV201) or $39 \mathrm{~h}$ (BM058) of exposure to hydrocarbons. Oceanospirillales became the dominant species, indicating the rapid response of the marine community to oil spills. In the StressChip data, a total of 14 Oceanospirillales probes from 7 species (Marinomonas sp. MED121, Chromohalobacter salexigens DSM 3043, Alcanivorax borkumensis SK2, Kangiella koreensis DSM 16069, Alcanivorax sp. DG881, Hahella chejuensis KCTC 2396, and Halomonas halodenitrificans) were detected with $10 \pm 2$ probes in plume and $5 \pm 2$ probes in nonplume communities. Halomonas halodenitrificans was detected in plume communities only. In contrast to data from 454 pyro-sequencing or clone library sequencing of $16 \mathrm{~S}$ rRNA genes from plume communities, the relative abundances of the detected probes at the phyla level were similar between plume and nonplume communities except for slight changes in Actinobacteria and Firmicutes (Figure S2, Supporting Information). Methylotrophs were found in previous metatranscriptomic studies of plume (BM058 and OV201) communities taken in August 2010 and later. ${ }^{65,66}$ The probes of four methylotrophs from Methylococcaceae, Methylophaga, and Methylophilaceae were also detected by StressChip in both plume and nonplume communities.

In summary, the consistency of the abundance of stress response genes with habitat conditions and the application of the StressChip to oil spill samples indicated that the StressChip is a powerful, rapid, and cost-effective high-throughput tool for assessing the responses of microbial communities to environmental stresses. It is well-known that the global environment is changing; information provided by the StressChip could be valuable for decision-making within the context of ecosystem management, environmental cleanup, bioremediation and restoration, environmental engineering, and applied microbiology. Although omics analysis of microbial communities offers the possibility of understanding "who is there" and "what they are doing", 69 challenges in data mining and issues associated with random sampling/under sampling still remain. ${ }^{70}$ A combination of microarray (e.g., StressChip) and high throughput sequencing (e.g., metagenomics, metatranscriptomics) will allow a comprehensive examination of the complex microbial community responses to environmental changes.

\section{ASSOCIATED CONTENT}

\section{Supporting Information}

Details of the metagenomes used for analysis of distributions of stress function genes and StressChip data of deepwater horizon oil spill plume samples. This information is available free of charge via the Internet at http://pubs.acs.org.

\section{AUTHOR INFORMATION}

\section{Corresponding Author}

*Phone: (405)325-6073; fax: (405)325-7552; e-mail: jzhou@ ou.edu.

\section{Notes}

The authors declare no competing financial interest.

\section{ACKNOWLEDGMENTS}

This work has been supported by ENIGMA under contract No. DE-AC02-05CH11231 by the Office of Science, Office of Biological and Environmental Research, of the U.S. Department of Energy; contract DE-SC0004601 through Biological Systems Research on the Role of Microbial Communities in Carbon Cycling Program by the US Department of Energy; NSF Macrosystems Biology project EF-1065844 through the Macrosystems Biology Program and Project 2007-35319-18305 through the NSF-USDA Microbial Observatories Program.

\section{REFERENCES}

(1) Wick, L. M.; Egli, T. Molecular components of physiological stress responses in Escherichia coli. Adv. Biochem. Eng. Biotechnol. 2004, 89, 145.

(2) Zhou, J.; He, Q.; Hemme, C. L.; Mukhopadhyay, A.; Hillesland, K.; Zhou, A.; He, Z.; Van Nostrand, J. D.; Hazen, T. C.; Stahl, D. A.; Wall, J. D.; Arkin, A. P. How sulphate-reducing microorganisms cope with stress: Lessons from systems biology. Nat. Rev. Microbiol. 2011, 9, 452466.

(3) Schweder, T.; Hecker, M. Monitoring of stress responses. Adv. Biochem. Eng. Biotechnol. 2004, 89, 47-71.

(4) Aguilar, P. S.; Hernandez-Arriaga, A. M.; Cybulski, L. E.; Erazo, A. C.; de Mendoza, D. Molecular basis of thermosensing: A twocomponent signal transduction thermometer in Bacillus subtilis. EMBO J. 2001, 20, 1681-1691.

(5) Schulz, A.; Schumann, W. hrcA, the first gene of the Bacillus subtilis dnaK operon encodes a negative regulator of class I heat shock genes. J. Bacteriol. 1996, 178, 1088-1093.

(6) Gouesbet, G.; Jebbar, M.; Talibart, R.; Bernard, T.; Blanco, C. Pipecolic acid is an osmoprotectant for Escherichia coli taken up by the general osmoporters ProU and ProP. Microbiology 1994, 140, 24152422.

(7) Haardt, M.; Kempf, B.; Faatz, E.; Bremer, E. The osmoprotectant proline betaine is a major substrate for the binding-protein-dependent 
transport system ProU of Escherichia coli K-12. Mol. Gen. Genet. 1995, 246, 783-786.

(8) He, Z.; van Nostrand, J. D.; Deng, Y.; Zhou, J. Development and applications of functional gene microarrays in the analysis of the functional diversity, composition, and structure of microbial communities. Front. Environ. Sci. Eng. China 2011, 5, 1-20.

(9) Marshall, I. P. G.; Berggren, D. R. V.; Azizian, M. F.; Burow, L. C.; Semprini, L.; Spormann, A. M. The Hydrogenase Chip: A tiling oligonucleotide DNA microarray technique for characterizing hydrogen-producing and -consuming microbes in microbial communities. ISME J. 2012, 6, 814-826.

(10) Dugat-Bony, E.; Missaoui, M.; Peyretaillade, E.; Biderre-Petit, C.; Bouzid, O.; Gouinaud, C.; Hill, D.; Peyret, P. HiSpOD: Probe design for functional DNA microarrays. Bioinformatics 2011, 27, 641-648.

(11) He, Z.; Deng, Y.; Zhou, J. Development of functional gene microarrays for microbial community analysis. Curr. Opin. Biotechnol. 2012, 23, 49-55.

(12) He, Z.; Van Nostrand, J. D.; Zhou, J. Applications of functional gene microarrays for profiling microbial communities. Curr. Opin. Biotechnol. 2012, 23, 460-466.

(13) He, Z.; Gentry, T. J.; Schadt, C. W.; Wu, L.; Liebich, J.; Chong, S. C.; Huang, Z.; Wu, W.; Gu, B.; Jardine, P.; Criddle, C.; Zhou, J. GeoChip: A comprehensive microarray for investigating biogeochemical, ecological and environmental processes. ISME J. 2007, 1, 67-77.

(14) He, Z.; Deng, Y.; Van Nostrand, J. D.; Tu, Q.; Xu, M.; Hemme, C. L.; Li, X.; Wu, L.; Gentry, T. J.; Yin, Y.; Liebich, J.; Hazen, T. C.; Zhou, J. GeoChip 3.0 as a high-throughput tool for analyzing microbial community composition, structure and functional activity. ISME J. 2010, 4, 1167-1179.

(15) He, Z.; Xu, M.; Deng, Y.; Kang, S.; Kellogg, L.; Wu, L.; Van Nostrand, J. D.; Hobbie, S. E.; Reich, P. B.; Zhou, J. Metagenomic analysis reveals a marked divergence in the structure of belowground microbial communities at elevated $\mathrm{CO}_{2}$. Ecol. Lett. 2010, 13, 564-575.

(16) Zhou, J.; Xue, K.; Xie, J.; Deng, Y.; Wu, L.; Cheng, X.; Fei, S.; Deng, S.; He, Z.; Van Nostrand, J. D.; Luo, Y. Microbial mediation of carbon-cycle feedbacks to climate warming. Nat. Clim. Change 2012, 2, 106-110.

(17) Rhee, S.-K.; Liu, X.; Wu, L.; Chong, S. C.; Wan, X.; Zhou, J. Detection of genes involved in biodegradation and biotransformation in microbial communities by using 50-mer oligonucleotide microarrays. Appl. Environ. Microbiol. 2004, 70, 4303-4317.

(18) Tiquia, S. M.; Wu, L.; Chong, S. C.; Passovets, S.; Xu, D.; Xu, Y.; Zhou, J. Evaluation of 50-mer oligonucleotide arrays for detecting microbial populations in environmental samples. Biotechniques 2004, 36, 664-675.

(19) He, Z.; Wu, L.; Li, X.; Fields, M. W.; Zhou, J. Empirical establishment of oligonucleotide probe design criteria. Appl. Environ. Microbiol. 2005, 71, 3753-3760.

(20) Li, X.; He, Z.; Zhou, J. Selection of optimal oligonucleotide probes for microarrays using multiple criteria, global alignment and parameter estimation. Nucleic Acids Res. 2005, 33, 6114-6123.

(21) Liebich, J.; Schadt, C. W.; Chong, S. C.; He, Z.; Rhee, S.-K.; Zhou, $\mathrm{J}$. Improvement of oligonucleotide probe design criteria for functional gene microarrays in environmental applications. Appl. Environ. Microbiol. 2006, 72, 1688-1691.

(22) Wu, L.; Liu, X.; Schadt, C. W.; Zhou, J. Microarray-based analysis of subnanogram quantities of microbial community DNAs by using whole-community genome amplification. Appl. Environ. Microbiol. 2006, 72, 4931-4941.

(23) Liang, Y.; He, Z.; Wu, L.; Deng, Y.; Li, G.; Zhou, J. Development of a common oligonucleotide reference standard for microarray data normalization and comparison across different microbial communities. Appl. Environ. Microbiol. 2010, 76, 1088-1094.

(24) Gao, H.; Yang, Z. K.; Gentry, T. J.; Wu, L.; Schadt, C. W.; Zhou, J. Microarray-based analysis of microbial community RNAs by wholecommunity RNA amplification. Appl. Environ. Microbiol. 2007, 73, 563571.
(25) Hengge-Aronis, R. Interplay of global regulators and cell physiology in the general stress response of Escherichia coli. Curr. Opin. Microbiol. 1999, 2, 148-152.

(26) Weber, H.; Polen, T.; Heuveling, J.; Wendisch, V. F.; Hengge, R. Genome-wide analysis of the general stress response network in Escherichia coli: sigmaS-dependent genes, promoters, and sigma factor selectivity. J. Bacteriol. 2005, 187, 1591-1603.

(27) Engelmann, S.; Lindner, C.; Hecker, M. Cloning, nucleotide sequence, and regulation of katE encoding a sigma B-dependent catalase in Bacillus subtilis. J. Bacteriol. 1995, 177, 5598-605.

(28) Scott, J. M.; Haldenwang, W. G. Obg, an essential GTP binding protein of Bacillus subtilis, is necessary for stress activation of transcription factor sigma B. J. Bacteriol. 1999, 181, 4653-4660.

(29) Raskin, D. M.; Judson, N.; Mekalanos, J. J. Regulation of the stringent response is the essential function of the conserved bacterial $\mathrm{G}$ protein CgtA in Vibrio cholerae. Proc. Natl. Acad. Sci. U.S.A. 2007, 104, 4636-4641.

(30) Persky, N. S.; Ferullo, D. J.; Cooper, D. L.; Moore, H. R.; Lovett, S. T. The ObgE/CgtA GTPase influences the stringent response to amino acid starvation in Escherichia coli. Mol. Microbiol. 2009, 73, 253266.

(31) Wout, P.; Pu, K.; Sullivan, S. M.; Reese, V.; Zhou, S.; Lin, B.; Maddock, J. R. The Escherichia coli GTPase CgtAE cofractionates with the 50S ribosomal subunit and interacts with SpoT, a ppGpp synthetase/hydrolase. J. Bacteriol. 2004, 186, 5249-5257.

(32) Schumann, W. Regulation of the heat shock response in Escherichia coli and Bacillus subtilis. J. Biosci. 1996, 21, 133-148.

(33) Phadtare, S.; Alsina, J.; Inouye, M. Cold-shock response and coldshock proteins. Curr. Opin. Microbiol. 1999, 2, 175-180.

(34) Jiang, W.; Hou, Y.; Inouye, M. CspA, the major cold-shock protein of Escherichia coli, is an RNA chaperone. J. Biol. Chem. 1997, 272, 196-202.

(35) Mazzon, R. R.; Lang, E. A. S.; Braz, V. S.; Marques, M. V. Characterization of Caulobacter crescentus response to low temperature and identification of genes involved in freezing resistance. FEMS Microbiol. Lett. 2008, 288, 178-185.

(36) Kempf, B.; Bremer, E. Uptake and synthesis of compatible solutes as microbial stress responses to high-osmolality environments. Arch. Microbiol. 1998, 170, 319-330.

(37) von Blohn, C.; Kempf, B.; Kappes, R. M.; Bremer, E. Osmostress response in Bacillus subtilis: Characterization of a proline uptake system (OpuE) regulated by high osmolarity and the alternative transcription factor sigma B. Mol. Microbiol. 1997, 25, 175-187.

(38) Spiegelhalter, F.; Bremer, E. Osmoregulation of the opuE proline transport gene from Bacillus subtilis: Contributions of the sigma A- and sigma B-dependent stress-responsive promoters. Mol. Microbiol. 1998, 29, 285-296.

(39) Fuangthong, M.; Herbig, A. F.; Bsat, N.; Helmann, J. D. Regulation of the Bacillus subtilis fur and perR genes by PerR: not all members of the PerR regulon are peroxide inducible. J. Bacteriol. 2002, 184, 3276-3286.

(40) Pomposiello, P. J.; Demple, B. Redox-operated genetic switches: The SoxR and OxyR transcription factors. Trends Biotechnol. 2001, 19, $109-114$.

(41) Mostertz, J.; Scharf, C.; Hecker, M.; Homuth, G. Transcriptome and proteome analysis of Bacillus subtilis gene expression in response to superoxide and peroxide stress. Microbiology 2004, 150, 497-512.

(42) Govantes, F.; Orjalo, A. V.; Gunsalus, R. P. Interplay between three global regulatory proteins mediates oxygen regulation of the Escherichia coli cytochrome d oxidase (cydAB) operon. Mol. Microbiol. 2000, 38, 1061-1073.

(43) Spiro, S.; Guest, J. R. Adaptive responses to oxygen limitation in Escherichia coli. Trends Biochem. Sci. 1991, 16, 310-314.

(44) Nakano, M. M.; Zuber, P. Anaerobic growth of a "strict aerobe" (Bacillus subtilis). Annu. Rev. Microbiol. 1998, 52, 165-190.

(45) Kruger, S.; Hecker, M. Regulation of the putative bglPH operon for aryl-beta-glucoside utilization in Bacillus subtilis. J. Bacteriol. 1995, $177,5590-5597$. 
(46) Webb, D. C.; Rosenberg, H.; Cox, G. B. Mutational analysis of the Escherichia coli phosphate-specific transport system, a member of the traffic ATPase (or ABC) family of membrane transporters. A role for proline residues in transmembrane helices. J. Biol. Chem. 1992, 267, 24661-24668.

(47) Torriani, A. From cell membrane to nucleotides: The phosphate regulon in Escherichia coli. Bioessays 1990, 12, 371-376.

(48) Allenby, N. E. E.; O'Connor, N.; Prágai, Z.; Carter, N. M.; Miethke, M.; Engelmann, S.; Hecker, M.; Wipat, A.; Ward, A. C.; Harwood, C. R. Post-transcriptional regulation of the Bacillus subtilis pst operon encoding a phosphate-specific $\mathrm{ABC}$ transporter. Microbiology 2004, 150, 2619-2628.

(49) Fischer, R.-J.; Oehmcke, S.; Meyer, U.; Mix, M.; Schwarz, K.; Fiedler, T.; Bahl, H. Transcription of the pst operon of Clostridium acetobutylicum is dependent on phosphate concentration and $\mathrm{pH}$. $J$. Bacteriol. 2006, 188, 5469-5478.

(50) Fiedler, T.; Mix, M.; Meyer, U.; Mikkat, S.; Glocker, M. O.; Bahl, H.; Fischer, R.-J. The two-component system PhoPR of Clostridium acetobutylicum is involved in phosphate-dependent gene regulation. $J$. Bacteriol. 2008, 190, 6559-6567.

(51) Nikata, T.; Sakai, Y.; Shibata, K.; Kato, J.; Kuroda, A.; Ohtake, H. Molecular analysis of the phosphate-specific transport (pst) operon of Pseudomonas aeruginosa. Mol. Gen. Genet. 1996, 250, 692-698.

(52) N'Guessan, A. L.; Elifantz, H.; Nevin, K. P.; Mouser, P. J.; Methe, B.; Woodard, T. L.; Manley, K.; Williams, K. H.; Wilkins, M. J.; Larsen, J. T.; Long, P. E.; Lovley, D. R. Molecular analysis of phosphate limitation in Geobacteraceae during the bioremediation of a uranium-contaminated aquifer. ISME J. 2009, 4, 253-266.

(53) Yan, D. Protection of the glutamate pool concentration in enteric bacteria. Proc. Natl. Acad. Sci. U.S.A. 2007, 104, 9475-9480.

(54) Wray, L. V.; Ferson, A. E.; Rohrer, K.; Fisher, S. H. TnrA, a transcription factor required for global nitrogen regulation in Bacillus subtilis. Proc. Natl. Acad. Sci. U.S.A. 1996, 93, 8841-8845.

(55) Goff, S. A.; Goldberg, A. L. Production of abnormal proteins in $E$. coli stimulates transcription of ion and other heat shock genes. Cell 1985, 41, 587-595.

(56) Dong, H.; Nilsson, L.; Kurland, C. Gratuitous overexpression of genes in Escherichia coli leads to growth inhibition and ribosome destruction. J. Bacteriol. 1995, 177, 1497-1504.

(57) Kosinski, M. J.; Rinas, U.; Bailey, J. E. Proteolytic response to the expression of an abnormal beta-galactosidase in Escherichia coli. Appl. Microbiol. Biotechnol. 1992, 37, 335-341.

(58) Jürgen, B.; Hanschke, R.; Sarvas, M.; Hecker, M.; Schweder, T. Proteome and transcriptome based analysis of Bacillus subtilis cells overproducing an insoluble heterologous protein. Appl. Microbiol. Biotechnol. 2001, 55, 326-332.

(59) Kruger, E.; Witt, E.; Ohlmeier, S.; Hanschke, R.; Hecker, M. The Clp proteases of Bacillus subtilis are directly involved in degradation of misfolded proteins. J. Bacteriol. 2000, 182, 3259-3265.

(60) Derré, I.; Rapoport, G.; Msadek, T. CtsR, a novel regulator of stress and heat shock response, controls $c l p$ and molecular chaperone gene expression in Gram-positive bacteria. Mol. Microbiol. 1999, 31, $117-131$.

(61) Hazen, T. C.; Dubinsky, E. A.; DeSantis, T. Z.; Andersen, G. L.; Piceno, Y. M.; Singh, N.; Jansson, J. K.; Probst, A.; Borglin, S. E.; Fortney, J. L.; Stringfellow, W. T.; Bill, M.; Conrad, M. E.; Tom, L. M.; Chavarria, K. L.; Alusi, T. R.; Lamendella, R.; Joyner, D. C.; Spier, C.; Baelum, J.; Auer, M.; Zemla, M. L.; Chakraborty, R.; Sonnenthal, E. L.; D’haeseleer, P.; Holman, H.-Y. N.; Osman, S.; Lu, Z.; Van Nostrand, J. D.; Deng, Y.; Zhou, J.; Mason, O. U. Deep-sea oil plume enriches indigenous oil-degrading bacteria. Science 2010, 330, 204-208.

(62) Lu, Z.; Deng, Y.; Van Nostrand, J. D.; He, Z.; Voordeckers, J.; Zhou, A.; Lee, Y.-J.; Mason, O. U.; Dubinsky, E. A.; Chavarria, K. L.; Tom, L. M.; Fortney, J. L.; Lamendella, R.; Jansson, J. K.; D’Haeseleer, P.; Hazen, T. C.; Zhou, J. Microbial gene functions enriched in the deepwater horizon deep-sea oil plume. ISME J. 2012, 6, 451-460.

(63) Cases, I.; de Lorenzo, V.; Ouzounis, C. A. Transcription regulation and environmental adaptation in bacteria. Trends Microbiol. 2003, 11, 248-253.
(64) Konstantinidis, K. T.; Tiedje, J. M. Trends between gene content and genome size in prokaryotic species with larger genomes. Proc. Natl. Acad. Sci. U.S.A. 2004, 101, 3160-3165.

(65) Kessler, J. D.; Valentine, D. L.; Redmond, M. C.; Du, M.; Chan, E. W.; Mendes, S. D.; Quiroz, E. W.; Villanueva, C. J.; Shusta, S. S.; Werra, L. M.; Yvon-Lewis, S. A.; Weber, T. C. A persistent oxygen anomaly reveals the fate of spilled methane in the deep Gulf of Mexico. Science 2011, 331, 312-315.

(66) Mason, O. U.; Hazen, T. C.; Borglin, S.; Chain, P. S. G.; Dubinsky, E. A.; Fortney, J. L.; Han, J.; Holman, H. N.; Hultman, J.; Lamendella, R.; Mackelprang, R.; Malfatti, S.; Tom, L. M.; Tringe, S. G.; Woyke, T.; Zhou, J.; Rubin, E. M.; Jansson, J. K. Metagenome, metatranscriptome and single-cell sequencing reveal microbial response to Deepwater Horizon oil spill. ISME J 2012, 6, 1715-1727.

(67) Valentine, D. L.; Kessler, J. D.; Redmond, M. C.; Mendes, S. D.; Heintz, M. B.; Farwell, C.; Hu, L.; Kinnaman, F. S.; Yvon-Lewis, S.; Du, M.; Chan, E. W.; Tigreros, F. G.; Villanueva, C. J. Propane respiration jump-starts microbial response to a deep oil spill. Science 2010, 330, 208-211.

(68) Lauro, F. M.; McDougald, D.; Thomas, T.; Williams, T. J.; Egan, S.; Rice, S.; DeMaere, M. Z.; Ting, L.; Ertan, H.; Johnson, J.; Ferriera, S.; Lapidus, A.; Anderson, I.; Kyrpides, N.; Munk, A. C.; Detter, C.; Han, C. S.; Brown, M. V.; Robb, F. T.; Kjelleberg, S.; Cavicchioli, R. The genomic basis of trophic strategy in marine bacteria. Proc. Natl. Acad. Sci. U.S.A. 2009, 106, 15527-15533.

(69) Jansson, J. K.; Neufeld, J. D.; Moran, M. A.; Gilbert, J. A. Omics for understanding microbial functional dynamics. Environ. Microbiol. 2012, $14,1-3$.

(70) Zhou, J.; Wu, L.; Deng, Y.; Zhi, X.; Jiang, Y.; Tu, Q.; Xie, J.; Van Nostrand, J. D.; He, Z.; Yang, Y. Reproducibility and quantitation of amplicon sequencing-based detection. ISME J. 2011, 5, 1303-1313. 